\title{
Providing a Safe, In-Person, Residential College Experience During the COVID-19 Pandemic
}

\author{
Scott A. Travis ${ }^{1}$, Aaron A. Best ${ }^{2}$, Kristyn S. Bochniak ${ }^{1}$, Nicole D. Dunteman ${ }^{1}$, \\ Jennifer Fellinger ${ }^{1}$, Peter D. Folkert ${ }^{1}$, Timothy Koberna ${ }^{1}$, Benjamin G. Kopek ${ }^{2 *}$, \\ Brent P. Krueger ${ }^{3}$, Jeff Pestun ${ }^{1}$, Michael J. Pikaart ${ }^{3}$, Cindy Sabo ${ }^{1}$ and Alex J. Schuitema ${ }^{1}$ \\ ${ }^{1}$ Hope College, Holland, MI, United States, ${ }^{2}$ Department of Biology, Hope College, Holland, MI, United States, ${ }^{3}$ Department \\ of Chemistry, Hope College, Holland, MI, United States
}

\section{OPEN ACCESS}

Edited by:

Allen C. Meadors,

Independent Researcher, Seven

Lakes, United States

Reviewed by:

Irene Pittman Aiken,

University of North Carolina at Pembroke, United States

Junfeng Wang,

University of Illinois at Springfield,

United States

${ }^{*}$ Correspondence: Benjamin G. Kopek kopek@hope.edu

Specialty section: This article was submitted to Public Health Education and

Promotion,

a section of the journal Frontiers in Public Health

Received: 05 March 2021 Accepted: 24 May 2021

Published: 23 June 2021

Citation:

Travis SA, Best AA, Bochniak KS, Dunteman ND, Fellinger J, Folkert $P D$, Koberna T, Kopek BG, Krueger BP,

Pestun J, Pikaart MJ, Sabo C and Schuitema AJ (2021) Providing a Safe,

In-Person, Residential College

Experience During the COVID-19

Pandemic.

Front. Public Health 9:672344.

doi: 10.3389/fpubh.2021.672344
Due to the COVID-19 pandemic, higher education institutions were forced to make difficult decisions regarding the 2020-2021 academic year. Many institutions decided to have courses in an online remote format, others decided to attempt an in-person experience, while still others took a hybrid approach. Hope College (Holland, MI) decided that an in-person semester would be safer and more equitable for students. To achieve this at a residential college required broad collaboration across multiple stakeholders. Here, we share lessons learned and detail Hope College's model, including wastewater surveillance, comprehensive testing, contact tracing, and isolation procedures that allowed us to deliver on our commitment of an in-person, residential college experience.

Keywords: SARS-CoV2 (COVID-19), virology, public health, undergraduate college education, wastewater, COVID19 testing

\section{INTRODUCTION}

Hope College is a 4-year residential institution located within the city of Holland, MI (pop. 30,300). The college has a current enrollment of 3,061 undergraduates served by 328 instructional faculty. Several months before the start of the fall 2020 semester, Hope College President, Matthew Scogin, committed to students and families to do everything possible "to provide an in-person experience for all our students, which includes in-person classes and on-campus living" (1). On May 20, 2020, a framework was shared to re-open the campus for safe, in-person living, and learning. It was our intent that this framework would lead to a safer and more equitable learning environment for all students. A recent Gallup study across higher education suggests it may also be a better one, finding that students who transitioned from an in-person learning environment to online learning said the quality of their education experience declined (2). Anecdotally, but in agreement with the Gallup study, Hope College professors reported that when the college was online during the Spring 2020 semester students could be seen taking exams in cars outside the local library due to a lack of reliable internet access at home. Thus, our desire to provide an in-person college experience was driven by the best interest of our students.

Our framework for a return to an in-person college experience for the 2020-2021 academic year included starting classes 2 weeks earlier than normal and reducing break days to complete the semester before Thanksgiving, adapting instructional spaces, implementing safeguards and health screens with accountability, and frequently communicating with students, families, and employees. Our plans also included strategies for student testing, contact tracing, and isolation. The outcomes and lessons learned from these strategies are outlined here with the hope that others can learn from our work to provide safe, in-person learning experiences of their own (Figure 1). 
$\underline{\text { July }}$

The test team was created. A testing plan was shared with employees, students and

families. First positive cases were identified during pre-arrival testing with at-home kits.

Positive cases during this time isolated at home.

\title{
August 12-18
}

A test center opened for arrival testing conducted by a third-party provider. Positive cases identified during this time were isolated and close contacts quarantined. The baseline goal was accomplished.

\begin{abstract}
August 19-31
Operations shifted to surveillance testing a $1 \%$ sample of students. After 11 days, the first positive cases after the beginning of classes were identified. Follow up testing based on wastewater began. All symptomatic and asymptomatic cases as well as close contacts were isolated and quarantined.
\end{abstract}

\section{September}

The first full residence hall follow up based on wastewater was conducted. A public dashboard was published. New rapid tests were procured that could be administered internally.

\section{October}

The 7-day positive test rate reached a semester low of $0.2 \%$ on Oct. 12 . Cases were on the rise in the surrounding county and state. Community spread began to impact campus on Oct. 27. Testing capacity was increased in order to respond appropriately.

\section{November}

While below county, state and national rates, the 7-day positive test rate reached a semester high of $7.7 \%$ on Nov. 11 . After which, testing volume remained high and the 7-day positive test rate dropped. Departure testing for students returning to an immunocompromised relative was conducted. The test center completed operations on Nov. 24 and spring pre-arrival test kits were distributed.

FIGURE 1 | Timeline overview of Hope College's Fall 2020 semester highlighting various aspects of our mitigation strategy and major events.

\section{COMPREHENSIVE TEAM APPROACH}

As we prepared for the fall semester, it became clear that we would need to work together across multiple areas of the organization if our framework were to succeed. In July, a team was formed that consisted of two biology faculty members, two IT staff members, a residential life staff member, the head athletic trainer responsible for contact tracing, a vice president responsible for COVID-19 response and public affairs, the director (registered nurse) of the campus health center, and a team lead assigned from another area of college administration. Meeting at least three times a week throughout the semester, this group made sure that the testing, contact tracing, and quarantine and isolation aspects of our framework acted as a single process. Having a diverse cross-functional team played a critical role in sharing and interpreting data from multiple sources in order to take decisive actions when needed.

\section{TESTING}

Between July 29 and November 24, 2020, we conducted 10,700 tests at no cost to students and employees. Our testing plan was tailored for our community and informed by the expertise of public health officials and our faculty and staff. We recognized that challenges could arise in both the supply chain for testing equipment and the turnaround time for test results. For this reason, it was critical to take a multi-faceted approach. Our testing plan was meant to supplement and monitor, not replace, all of the other protections put in place as part of our broad pandemic mitigation strategy.

\section{Baseline Testing}

Our first goal was to start the academic year with zero cases of COVID-19 on campus. To achieve a baseline of zero, students and employees were tested with an at-home kit sent directly to them (3). The kit featured a saliva-based test that was medicallysupervised via Zoom video conferencing. Partnering with Vault Health (NY), students and employees were tested 8-10 days before arrival. Because this test captured the result for only that particular moment in time, students and employees were expected to do everything possible to minimize their risk of exposure to the virus as they prepared to arrive on campus. A relatively small number of students, faculty, and staff were unable to complete the saliva-based test prior to arrival on campus. These individuals were required to get a rapid antigen 


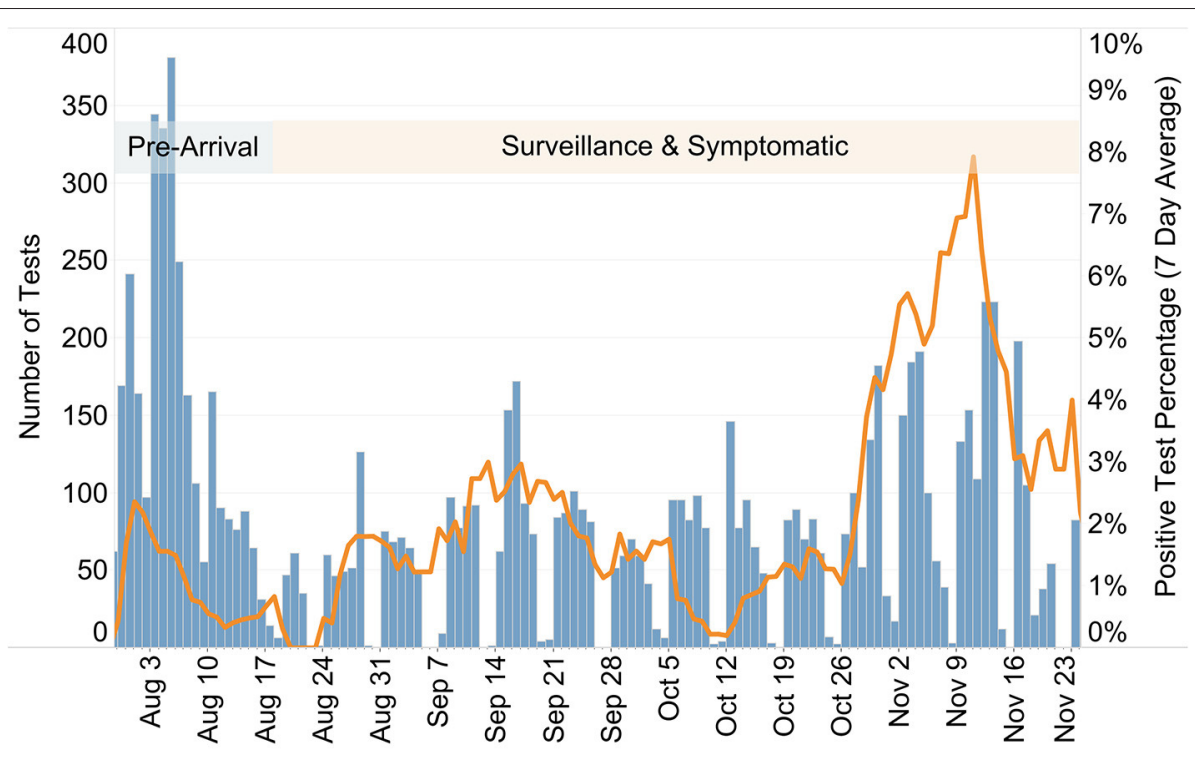

FIGURE 2 | Plot displaying the number of tests conducted each day (blue bars) and the 7-day running average of the positive-test percentage (orange line) at Hope College (MI) before and during the Fall 2020 semester. The semester began on August 17, separating pre-arrival testing from surveillance and symptomatic testing as indicated.

test performed on-site and were not allowed to check into oncampus housing (access card not activated) until they received a negative test. Results of the tests were communicated only to the student and members of the test team in accordance with HIPAA guidelines. The housing office was provided a list that indicated if a student was cleared to move in or needed testing upon arrival. Between the at-home and on-arrival testing, a total of 3,878 tests were administered as part of baseline testing. Thirty-five students tested positive with the at home test and were not allowed to travel to campus. Three students tested positive upon arrival and were immediately placed into isolation housing. No faculty or staff tested positive with pre-arrival testing. On the first day of classes (August 17, 2020), our $0.98 \%$ positive test rate was lower than the national positive rate of $6.1 \%$ and state positive rate of $2.5 \%$ according to the Johns Hopkins Coronavirus Resource Center (4) (Figure 2).

\section{Surveillance (Asymptomatic) Screening}

Our surveillance testing plan was developed to monitor the campus for the presence of SARS-CoV2, catching as many asymptomatic cases as possible, and containing the spread of the virus. As testing strategies were being developed, several mathematical models were published to predict the effectiveness of viral transmission mitigation strategies $(5,6)$. In these models, the greatest reduction in case number was achieved by many of our strategies (i.e., mask wearing, physical distancing, etc.). Therefore, we determined that a lower rate ( $1 \%$ of campus population daily) of surveillance screening would be sufficient to detect outbreaks in campus housing. This is a much lower testing frequency than advocated in some other models (7), but was determined to be our best strategy based on our constraints. We were able to contract with a service provider to enable rapid ( $15 \mathrm{~min}$ ) testing for surveillance that allowed for a maximum of 60 tests to be run per day. As new testing methods were introduced and reagents produced nationwide, our campus health team was able to begin administering rapid (15 min) antigen tests. Thus, our daily surveillance testing averaged 73 tests per day for the semester. Once the contracted service was complete ( 2 weeks before the end of the semester), all rapid antigen tests were run by the Hope College Health Center nursing team. When needed, we were able to perform large-scale testing events. Early in the semester, saliva-based PCR testing was used to conduct one of these testing events. As the semester progressed, testing events used the rapid antigen tests.

For surveillance testing, students were selected at random and the testing took place at the campus Test Center every weekday. Notifications and reminders were sent from a dedicated Test Center email account to the student's college-provided email account. In most cases, students had up to $48 \mathrm{~h}$ to complete their test. Out of 5,696 requests to test, only 24 failed or refused to be tested for a response rate of $99.6 \%$. If a student failed to show up for a test, then they would receive two email reminders on subsequent days. Students were then sent to the Student Development office for follow up with the judicial process if the individual still did not comply.

\section{Wastewater Surveillance Testing}

Between August 27 and September 6, the wastewater surveillance testing program was ramped up with coverage of approximately $55 \%$ of the entire student population, including $70 \%$ of those in college-owned housing. This led us to switch to a more targeted testing strategy based on wastewater data for the covered student population. Those living outside of the wastewater testing zones continued to be screened through randomized surveillance testing. 
Wastewater coming from nine specific residential zones on campus was collected using dedicated autosamplers each weekday, yielding $24 \mathrm{~h}$ composite samples. Each zone had between 100 and 250 residents. Wastewater samples were collected and analyzed for the presence of viral genomic material by quantitative PCR. This method allowed for same-day results regarding the presence or absence of viral genetic material in the campus wastewater zones. Thus, we were able to react quickly in response to infected individuals within campus housing even if those individuals were not showing symptoms. Follow-up testing of individuals based on wastewater samples was conducted on 29 different occasions between August 31 and November 16. On multiple occasions, as testing capacity allowed, entire residential halls were asked to test within $24 \mathrm{~h}$.

Including both the $1 \%$ sample and individual wastewater follow up testing, 5,696 surveillance tests were conducted during the semester, resulting in 57 positive cases (a 1\% positive rate) (Figure 2). It is important to note that these were asymptomatic cases (or more likely mildly symptomatic and not likely to seek testing) identified and isolated, with contact tracing leading to additional quarantined students.

\section{Subset Testing}

There were some groups of individuals, including residential life staff and student-athletes, that were tested regularly. While the Michigan Intercollegiate Athletic Association postponed conference competition, our athletic teams continued team activities and conducted additional testing regularly. Testing cadences for each team were executed from the NCAA recommendations. Recommendations were determined by risk of transmission while participating in sport. This was completed by athletic training staff in partnership with the overall testing process. An additional testing subset at the end of the semester included students who indicated they would be returning to housing during the time between semesters and would unavoidably be in close contact with an immunocompromised family member. For these situations, students were provided "peace of mind" testing prior to leaving campus.

\section{Symptomatic Testing}

Symptomatic testing was reserved for students who experienced and reported symptoms of COVID-19. These tests were conducted by registered nurses from the Hope College Health Center. Students were asked to self-quarantine until they received a test and result. Employees experiencing symptoms were asked to test through their healthcare provider. During the semester, 960 symptomatic tests were conducted, resulting in 124 positive cases. The positive rate for symptomatic tests was $12.9 \%$.

\section{CONTACT TRACING}

Students were also required to participate in the contact tracing process. Each positive case prompted a contact tracing investigation to determine close contacts. Close contacts were defined as individuals who had been within 6 feet of a positive case for a cumulative total of $15 \mathrm{~min}$ or more. As we began the semester, trained advocates, often college staff from other areas, helped students begin the process of identifying close contacts so that they were prepared to work with the health department. While the Ottawa County Department of Public Health remained a close partner all semester long, these investigations shifted increasingly to college staff as contact tracing resources in the surrounding community became unavailable. A contact tracing team of 7 individuals conducted over 150 investigations throughout the semester leading to 670 close contacts in quarantine. While our semester average of close contacts per positive case was between 4 and 5, we identified a trend of more close contacts per positive case in the latter part of the semester as, presumably, student adherence to safeguards lessened.

\section{ISOLATION AND QUARANTINE}

All students that tested positive for SARS-CoV2 were required to isolate. Isolation separated infected individuals from others and lasted 10 days from the first date of symptoms (or test date for asymptomatic cases). Quarantine separated and restricted the movement of people who were close-contacts with a known infected individual and lasted 14 days from last known contact. In general, isolation and quarantine resulted in students leaving their campus housing and moving into designated housing. However, in some cases (apartments, cottages) where all roommates were considered close contacts students had the option to remain in their original housing. Students were also allowed to go home to their permanent residence to quarantine or isolate unless instructed otherwise by the local health department. At the start of the semester, the college reserved 126 rooms for isolation and quarantine purposes. This increased to 176 rooms by the end of the semester. The peak of students in isolation and quarantine, including those in isolation or quarantine at home, was 369 on November 11. All courses made accommodations for remote learners (i.e., students in isolation or quarantine). Typically, this included streaming or recording of lectures and online submission of materials or exams.

A team of trained advocates and healthcare professionals supported students who were in isolation or quarantine to make their experience as comfortable as possible. These advocates helped with moving, informed students of resources, checked in on them, facilitated communication with faculty, and helped them understand their role in the contact tracing process. While in isolation or quarantine, students participated in classes remotely. Faculty were prepared to engage students in their courses using online tools. Dining services created a special menu and delivery service. Symptomatic students were asked to take their temperature and asymptomatic students were asked to monitor for symptoms. The process, including the availability of housing and advocates, applied to all students, whether they resided on or off-campus.

We used a symptom-based and time-based strategy, not a test-based strategy, to determine a return date for individuals diagnosed with confirmed or suspected COVID-19. This strategy took into account the time since the diagnosis and the time since recovery as well as the presence or absence of symptoms. The decision to end isolation or quarantine and return to campus was made in consultation with healthcare providers and the local health department. 
We observed 21 cases where a close contact student that went into isolation became symptomatic and tested positive. Thus, quarantining close contacts likely reduced the number of infections on campus. Our experience serves as an example of how contact tracing and quarantine procedures worked to mitigate spread.

\section{OTHER MITIGATION MEASURES}

\section{Masks}

As required by the Michigan Department of Health and Human Services order, students and employees were required to wear masks in all public spaces, including classrooms.

\section{Physical Distancing}

Prior to the academic year, faculty and staff determined capacity limits for classroom and laboratory spaces that would provide the recommended physical distancing ( 6 feet) between individuals. The registrar then determined which classes, based on enrollment, could fit within designated classroom spaces. If a large enough classroom could not be found, then the instructional modality was changed. For Fall 2020, 58\% of courses were conducted in the traditional (in-person) manner compared to $100 \%$ in all previous years. Eighteen percent of courses were taught in a completely online manner and the rest were taught in a hybrid manner (combination of in-person and online course environment).

\section{Screening Form}

Students who would be on campus were asked to complete a screening form that asked if they were experiencing any COVID-like symptoms. Students were asked, but not required, to complete this form. Participation in this screening form dropped from 1,882 submissions on the first day of classes to 316 on the final day of classes. This measure was deemed to not be effective and was not continued for the Spring semester.

Employees who were going to be on campus were required to complete a daily screening form for COVID-19 symptoms as directed by the Michigan Department of Occupational Health and Safety. If students were experiencing symptoms they were directed to the Campus Health Center while employees were directed to see their physician.

\section{Travel}

As mentioned in the Introduction, the academic calendar was modified to discourage opportunities for long distance travel. Breaks were limited to single days separated from weekends, such that there were never more than two consecutive days without courses in the fall semester. All faculty, staff, and students were also encouraged to minimize travel, though no formal restrictions were put into place. Hope College is tightly interwoven with the city of Holland, MI, which has a vibrant downtown area. Thus, it would have been impossible to restrict students from leaving campus.

\section{DISCUSSION}

As we prepared to continue in-person learning during the spring of 2021, we considered the following lessons and offer them to others preparing for similar situations:

- Information must be available and actionable. The teams involved in the various stages of the process (from wastewater results to quarantine capacity) need a consistent and accurate way to share information, interpret available data, and make data-driven decisions.

- Diverse perspectives lead to better decision-making. Having representatives from each area regularly meet to share information, have honest and difficult discussions, and make recommendations to decision-makers helps make sure we make the right decisions at the right time.

- A good working relationship with the local health department is critical. We follow the recommendation of the Centers for Disease Control and Prevention to work with our local health department and are fortunate to partner with the Ottawa County Department of Public Health. Meetings and follow up conversations are frequent and comprehensive.

- Constraints must be acknowledged and managed. We try to start with the ideal approach and work backward based on identified constraints. These could include testing capacity, staffing, housing capacity, regulations, or finances.

- Talented teams make difficult work possible. Including the COVID-19 Steering Committee and sub-teams around wastewater, testing operations, contact tracing, academics, safety operations, and housing, it is estimated that 150 employees, approximately $20 \%$ of our workforce, have had at least part of their job realigned to respond to COVID-19.

During a meeting on October 30, amid a local, state, and national outbreak, local health officials confirmed that our students were likely safer on campus within our framework than they were elsewhere. We note that our student population differs from the overall population of Michigan and the country with regard to age and underlying health conditions making such comparisons difficult. However, the Ottawa County Department of Public Health shared that while our campus situation reflected the reality of the broader West Michigan region where viral spread was picking up rapidly, because it is a highly controlled environment Hope was actually better positioned than our surrounding communities. We were able to quickly identify areas of viral spread, schedule tests, isolate and quarantine individuals, complete contact tracing, and notify close contacts very effectively and efficiently. This stands in contrast to what may have been experienced in communities with large universities (>20,000 students) where the incidence of infection was not sufficiently contained (8). Therefore, we recommend that all higher education institutions seek to implement a comprehensive framework similar to the one outlined here and implemented at Hope College.

\section{DATA AVAILABILITY STATEMENT}

The raw data supporting the conclusions of this article will be made available by the authors, without undue reservation. 


\section{AUTHOR CONTRIBUTIONS}

ST wrote the article. AB, KB, ND, JF, PF, TK, BGK, BPK, JP, MP, $\mathrm{CS}$, and $\mathrm{AS}$ edited the article. $\mathrm{AB}, \mathrm{BGK}, \mathrm{BPK}$, and MP performed wastewater testing. PF, AS, and ST analyzed non-wastewater related data. All authors contributed to the article and approved the submitted version.

\section{REFERENCES}

1. Fellinger J, Scogin M. Our Take: Hope committed to safe in-person start. Holland Sentinel. Available online at: https://www.hollandsentinel.com/opinion/ 20200811/our-take-hope-committed-to-safe-in-person-start (January 11, 2021).

2. State of the Student Experience: Fall 2020. Gallup, Inc. (2020). Available online at: https://www.gallup.com/education/327485/state- of-the-studentexperience-fall-2020.aspx (accessed December 20, 2020).

3. Vault Health/Covid-19 Testing. Available online at: https://www.vaulthealth. com/covid (accessed January 11, 2021).

4. Johns Hopkins Coronavirus Resource Center. Available online at: https:// coronavirus.jhu.edu/ (accessed January 28, 2021).

5. Gressman PT, Peck JR. Simulating COVID-19 in a university environment. arXiv:200603175[physics, q-bio]. (2020). Available online at: http://arxiv.org/abs/2006.03175 (accessed July 1, 2020).

6. Lopman B, Liu C, Le Guillou A, Lash TL, Isakov A, Jenness S. A model of COVID-19 transmission and control on university campuses. Epidemiology. (2020). doi: 10.1101/2020.06.23.20138677. [Epub ahead of print].

\section{FUNDING}

Funding for some wastewater analysis was provided by the Michigan Department of Environment, Great Lakes and Energy. The funders had no role in study design, data collection and analysis, decision to publish, or preparation of the manuscript.

7. Paltiel AD, Zheng A, Walensky RP. Assessment of SARS-CoV2 screening strategies to permit the safe reopening of college campuses in the United States. JAMA Netw Open. (2020) 3:e2016818. doi: 10.1001/jamanetworkopen.2020.16818

8. Leidner AJ. Opening of large institutions of higher education and county-level COVID-19 incidence - United States, July 6-September 17, 2020. MMWR Morb Mortal Wkly Rep. (2021) 70:14-9. doi: 10.15585/mmwr.mm7001a4

Conflict of Interest: The authors declare that the research was conducted in the absence of any commercial or financial relationships that could be construed as a potential conflict of interest.

Copyright (C) 2021 Travis, Best, Bochniak, Dunteman, Fellinger, Folkert, Koberna, Kopek, Krueger, Pestun, Pikaart, Sabo and Schuitema. This is an open-access article distributed under the terms of the Creative Commons Attribution License (CC BY). The use, distribution or reproduction in other forums is permitted, provided the original author(s) and the copyright owner(s) are credited and that the original publication in this journal is cited, in accordance with accepted academic practice. No use, distribution or reproduction is permitted which does not comply with these terms. 